\title{
Otimização do processo de colheita mecanizada de cana-de- açúcar
}

\section{Éver Santoro}

Programa de Pós Graduação em Engenharia de Produção, FEB-Unesp, Bauru, SP

\section{Adriana Cristina Cherri ${ }^{2}$}

Departamento de Matemática, Unesp - Univ Estadual Paulista, Bauru, SP

\section{Edilaine Martins Soler ${ }^{3}$}

Departamento de Matemática, Unesp - Univ Estadual Paulista, Bauru, SP

\begin{abstract}
Resumo. A cultura de cana-de-açúcar é muito importante para o agronegócio brasileiro, respondendo por $16 \%$ da matriz energética do país, sendo uma das mais limpas e renováveis do mundo. Com o aumento constante da produção e a mudança de paradigma de colheita a partir da mecanização, evidencia-se a necessidade de maior controle das atividades agrícolas, otimizando principalmente o processo de colheita por tratar-se de uma nova atividade mecanizada. Neste trabalho propomos um modelo matemático para otimizar o processo de colheita mecanizada da cana-de-açúcar, buscando através da análise de mapas reais de plantio traçar o melhor plano de colheita a ser realizado.
\end{abstract}

Palavras-chave. Cana-de-açúcar, colheita mecanizada, Modelagem Matemática

\section{Introdução}

A cana-de-açúcar está entre as culturas mais importantes do agronegócio brasileiro, sendo o Brasil o maior produtor mundial de açúcar e de álcool do planeta [3]. Com a expansão do setor sucroalcooleiro no Brasil, um novo padrão tecnológico na produção de açúcar e álcool se impõe a partir de mudanças no ambiente institucional, mormente com a promulgação da Lei 11.241/2002 [2], que limita a queima da cana e favorece a mecanização da colheita. O avanço da mecanização na colheita da cana-de-açúcar proporcionou o uso de novas tecnologias e ganho em produtividade para a cultura.

De acordo com [1], a colheita mecânica da cana traz ganhos ambientais e de saúde pública, principalmente por reduzir os danos ao meio ambiente e por dispensar a queima de resíduos. Além desses benefícios, a mecanização proporciona ganhos econômicos, pois diminui o custo de produção da lavoura, reduz os impactos ambientais e permite o aproveitamento da palha da cana para a geração de energia nas usinas e cobertura do solo.

\footnotetext{
1 eversantroro@gmail.com

2 adriana@fc.unesp.br

3 edilaine@fc.unesp.br
} 


\section{Descrição do Problema}

O problema estudado envolve o planejamento da rota da máquina colhedora e consiste em decidir qual a melhor rota a ser realizada, visto que é conhecido o layout do canavial. Neste problema, todas as linhas de cana devem ser percorridas de modo a minimizar o tempo de manobra da colhedora quando ela troca a linha de cana a ser colhida. Sabe-se que o tempo de manobra da máquina para trocar de linha de cana é muito alto e o custo da colheita mecanizada é representativo em relação ao custo total de produção da cana-de-açúcar.

Para modelar matematicamente este problema consideramos um grafo não orientado em que cada linha de cana corresponde a uma aresta limitada por dois vértices do grafo (cada vértice é um nó do grafo, sendo representado pelo início e fim da rua de cana). As arestas do grafo possuem custos associados que representam o tempo de manobra da máquina colhedora. Sabe-se que o tempo de manobra da máquina para trocar de linha de cana é muito alto. Assim, este problema reduz-se ao Problema do Carteiro Rural, em que dado um grafo $\mathrm{G}=(\mathrm{V}, \mathrm{A})$, em que $\mathrm{V}$ corresponde ao conjunte de vértices, com $\mathrm{V}=\left\{v_{1}, v_{2}, \ldots, v_{n}\right\}$, e $\mathrm{A}$ representa o conjunto de arestas entre os vértices, $\mathrm{A}=\{(i, j), i \neq j\}$. Definimos um subconjunto $A_{r} \subset A$, de arestas obrigatórias. $\mathrm{O}$ problema consiste em determinar um caminho fechado de custo mínimo, partindo de um ponto de origem e passando por cada aresta de $A_{r}$ uma vez.

\section{Conclusão}

O modelo matemático desenvolvido foi implementado em linguagem de programação Java integrado com o solver CPLEX. Os resultados preliminares obtidos até o momento, com simulações baseadas em dados reais fornecidos por uma indústria de açúcar e álcool da região de Catanduva, demonstram a eficiência do modelo em fornecer soluções que minimizam o tempo de manobra da colhedora e serão apresentados no evento.

\section{Agradecimentos}

Os autores agradecem o apoio do CNPQ (Processo n ${ }^{\circ} 477481 / 2013-2$ ).

\section{Referências}

[1] F. Furtado, Mecanização da colheita da cana traz benefício ambiental. Disponível em: $<$ http://cienciahoje.uol.com.br/noticias/agricultura-e-agronomia/mecanizacao-dacolheita-da-cana-traz-beneficio >. Acesso em: 22 fev. 2015.

[2] São Paulo (Estado). Resolução SMA n. 33, 21/06/2007, lei no 11.241/2002. Disponível em: $\quad<$ http://www.sigam.ambiente.sp.gov.br/sigam3/Repositorio/24/Documentos/Lei Estadual_11241_2002.pdf>. Acesso em: 05 mar. 2015

[3] P. R. Silva, F. C. Correa e W. J. Cortez, Controle estatístico aplicado ao processo de colheita mecanizada de cana de açúcar, Eng. Agrícola, vol. 28 (2), 292-304, (2008). 